\title{
The Neural System Underlying Chinese Logograph Reading
}

\author{
Li Hai Tan,* Ho-Ling Liu,† Charles A. Perfetti,‡ J ohn A. Spinks,§ Peter T. Fox," and J ia-Hong Gao"
}

*Laboratory for Language Neuroscience and Cognition, Department of Linguistics, University of Hong Kong, Pokfulam Road, Hong Kong; †Department of Medical Technology, Chang Gung University and Department of Diagnostic Radiology, Chang Gung Medical Center,

Taoyuan, Taiwan; łLearning Research and Development Center, University of Pittsburgh, Pittsburgh, Pennsylvania 15260; §Cognitive Science Program, University of Hong Kong, Pokfulam Road, Hong Kong; and "Research Imaging Center,

University of Texas Health Science Center, San Antonio, Texas 78284

Received J uly 31, 2000; published online March 19, 2001

Written Chinese as logographic script differs notably from alphabets such as English in visual form, orthography, phonology, and semantics. Thus, research on the Chinese language is important to advance our understanding of the universality and particularity of the organization of language systems in the brain. In this study, we examine the neural systems associated with logographic reading using functional magnetic resonance imaging. Two experimental tasks were devised, one based on semantic decision and the other on homophone decision. Compared to the fixation baseline, peak activations resulting from semantic as well as homophony decisions were localized in the left middle frontal gyrus (BA 9). Left inferior frontal cortex also mediated Chinese processing. In addition, more right hemisphere cortical regions (i.e., BAs 47/45, 7, 40/39, and the right visual system) were involved in reading $C$ hinese relative to reading English. This is attributed to the square shape of the logograph which requires an elaborated analysis of the spatial information and locations of various strokes comprising the logographic character. We suggest that the left middle frontal area (BA 9) coordinates and integrates the intensive visuospatial analysis demanded by logographs' square configuration and the semantic (or phonological) analysis required by the present experimental tasks. Our study has implicated brain regions common to both logographic and alphabetic languages as well as brain regions specialized in processing logographs. o 2001 Academic Press

Key Words: fMRI; reading; reading Chinese; BA 9; word recognition; Chinese character identification.

\section{INTRODUCTION}

Recent research measuring task-related changes in regional cerebral blood flow and oxygenation with positron emission tomography (PET) and functional magnetic resonance imaging ( $\mathrm{fMRI}$ ) has yiel ded impor- tant insights into the neural systems underlying word recognition and reading in the human brain. A largescale distributed cortical network, including left frontal, temporal, and occipital cortices, has been suggested to mediate the processing of visuo-orthographic, phonologic, semantic, and syntactic constituents of alphabetic words (Binder et al., 1995; Bookheimer et al., 1995; Brunswick et al., 1999; Caplan et al., 2000; Demonet et al., 1992; Desmond et al., 1995; Fiez et al., 1999; Gabrieli et al., 1996; Howard et al., 1992; J ust et al., 1999; More and Price, 1999; Petersen et al., 1988; Poldrack et al., 1999; Price et al., 1994; Shaywitz et al., 1996). Due to the variety of written languages, investigations with different written scripts have added to the challenge of mapping language functions onto the brain. There are several studies implicating distinct cortical areas that are associated with the processing of different languages (Dehaene et al., 1997; Gandour et al., 2000; Kim et al., 1997; Mazoyer et al., 1993; N eville et al., 1998; Paulesu et al., 2000; Perani et al., 1996). Other studies, however, have reported that common neural networks are recruited during the recognition of various written scripts (Hagoort et al., 1999; I lles et al., 1999; Klein et al., 1994, 1995).

Research on written Chinese will advance our understanding of the commonality and particularity of the organization of language systems in the brain, as the design principle of the Chinese writing system differs markedly from the design principle of alphabetic systems such as English and French. Written Chinese is considered to be a logographic system, in which characters as a basic writing unit possess a number of strokes that are packed into a square shape. Chinese characters map onto meaningful morphemes rather than phonemes in the spoken language, implying that regular or quasi-regular grapheme-phoneme conversions that exist in all al phabetic languages (e.g., the letter $\mathrm{b}$ is pronounced /b/) are impossible in Chinese (Plaut et al., 1996; Tan and Perfetti, 1998). Rather, a 
Chinese characters' pronunciation is defined at the syllable level and must be learned through rote memory of the association of visual character form and sound, occasionally with the aid of subcharacter units that are themselves real characters. These unique characteristics imply that some of the neurocognitive mechanisms underlying Chinese logographic reading may differ from those underlying alphabetic word reading (Tan and Perfetti, 1998; Weber-Fox and Neville, 1996).

Most of the past research with Chinese has adopted the visual hemifield paradigm in an attempt to ascertain whether a Chinese characters' unique square configuration leads to the dominance of the right cerebral hemisphere. So far, the conclusions have been contentious (Cheng and Yang, 1988; Fang, 1997; Naeser and Chan, 1980; Tzeng et al., 1979). More recent investigations with fMRI suggest that, although brain activations during reading aloud of Chinese characters are bi-lateralized (Tan et al., 2001), silent reading of Chinese is dominated by the activity of the left hemisphere (Chee et al., 1999a, 1999b; Tan et al., 2000). Neuroimaging findings with J apanese Kanji, which is similar to Chinese characters in orthography, seem to provide a corroboration of the results from Chinese reading ( $\mathrm{Fu}$ jimaki et al., 1999; Uchida et al., 1999).

Despite the absence of an interhemispheric difference in processing logographic Chinese and al phabetic English, reading in Chinese results in some important neural activity that is rarely observed during the reading of English. In our previous research (Tan et al., 2000; Xiong et al., 2000) with single characters and two-character Chinese words, subjects covertly generated a word that was semantically related to each viewed stimulus. While the left inferior prefrontal areas (Brodmann's areas [BA] 47 and 45) were involved in the semantic generation of Chinese stimuli, a finding that agrees with the finding of the loci of semantic processing and meaning retrieval of English words (e.g., Buckner and Petersen, 1996; Buckner et al., 1995; Demb et al., 1995; Gabrieli et al., 1996; Petersen et al., 1988; Ricci et al., 1999; Roskies et al., 1996; Wagner et al., 1997; reviewed by Price, 1997 and Gabrieli et al., 1998), peak activation during Chinese reading was localized in the middle frontal lobe (BA 9), a region that is rarely reported in neuroimaging studies of the processing of al phabetic words.

Our previous results (Tan et al., 2000) implicated a possible segregation of the cortical organization of written Chinese and alphabets. However, the word generation responses of each subject were not monitored during the fMRI study. Thus, cognitive processes involved in that task are not clear.

The objective of the present study was to further elucidate the neural system that contributes to reading Chinese. We used two experimental tasks: a semantic judgment task and a homophone judgment task. In the semantic task, subjects were asked to judge whether a a
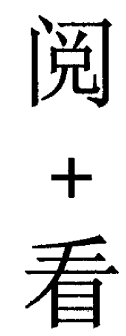

b

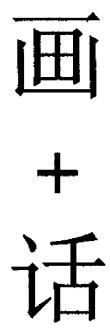

FIG. 1. Examples of experimental stimuli used in the experiment. In a, the subject judged whether the two Chinese characters were semantically related or not. The character above the fixation crosshair is pronounced /yue/, with a meaning of "view" and "read." The character below the fixation crosshair is pronounced /kan/, meaning "look" and "view." In b, the subject judged whether the two Chinese characters were homophones or not. The character above the fixation crosshair is pronounced/hua/, with a meaning of "draw." The character bel ow the fixation crosshair is also pronounced/hua/, meaning "talk" and "words." From these examples, we find that Chinese characters look very different from English words. Each Chinese character is made up of a number of strokes, the smallest writing unit of Chinese logographs. These strokes are assembled into a square shape according to stroke sequence rules that readers learn in primary school. For example, the character 阅 consists of the following 10 strokes: I J $、 \cdot 1 \mathrm{~J}-J$ L. The modern Chinese uses approximately 5000 characters and 420 distinct syllables (i.e., pronunciations, disregarding tone) (Tan and Perfetti, 1998). Thus, homophones abound. It is quite easy to find Chinese characters that are pronounced identically but look very different. In our study, the two characters exposed in each pair shared no visual similarity.

pair of Chinese characters exposed synchronously were semantically related. In the homophone task, subjects were required to decide whether a pair of Chinese characters exposed synchronously were homophones. For both tasks, we monitored the subjects' performance. To control for the effects of word familiarity on cognitive and neuronal activities (Fiez et al., 1999; Pugh et al., 1997), the stimuli used in our experiment were matched across frequencies of occurrences. More over, the two Chinese characters exposed in each pair shared no visuo-orthographic similarity so that the subject had to make a decision based on characters' semantic or phonological attributes rather than based on their visual properties. Figure 1 shows examples of experimental stimuli used in our study.

In this study, the experimental tasks alternated with a control task in which the subject maintained fixation on a crosshair. Functional brain activation was measured during each block, using fMRI. Comparisons of 
each of the two experimental tasks with the baseline allowed us to identify the holistic neural network active during reading Chinese.

\section{METHODS}

\section{Subjects}

Six male volunteers participated in this study. They gave informed consent in accordance with guidelines set by the U niversity of Texas Health Science Center at San Antonio (UTHSCSA). All subjects were native Chinese (Mandarin) speakers from mainland China, ranging in age from 29 to 40 years and living in the U.S. no more than 6 years.

All subjects were strongly right handed as judged by the handedness inventory devised by Snyder and Harris (1993). In this inventory, we adopted nine items involving unimanual tasks (tasks which can be done by only one hand). A 5-point Likert-type scale was used, with " 1 " representing exclusive left-hand use and " 5 " representing exclusive right-hand use. The items were: writing a letter, drawing a picture, throwing a ball, holding chopsticks, hammering a nail, brushing teeth, cutting with scissors, striking a match, and opening a door. The scores on the nine items were summed for each subject, with the lowest score (9) indicating exdusive left-hand use for all tasks, and the highest score (45) indicating exdusive right-hand use. All subjects had scores higher than 40.

\section{Materials and Behavioral Performance}

Forty-four pairs of semantically related Chinese characters and 44 pairs of homophones were used in this study. For the semantically related pairings, we asked 20 informants who were not participants of this study to assess their semantic relatedness in terms of a 7-point rating scale, ranging from 1 (not related at all) to 7 (very closely related). We added 50 pairs of semantically unrelated characters to serve as fillers in this rating scale. The ratings for the 44 semantically associated pairs ranged from 5.50 to 7.00 , with an average of $6.0(\mathrm{SD}=0.58)$. Homophones are pervasive in Chinese. However, Chinese is a tonal language that uses four distinctive tones (in Mandarin), and a complete specification of a Chinese syllable (pronunciation) involves both its segmental (consonants plus vowels) and suprasegmental tonal information (Spinks et al., 2000). To avoid any possible effects from tone variation, the 44 pairs of homophones used in this study satisfied the constraint that they shared both segments as well as tones.

All Chinese characters used were common characters with a frequency of occurrence no fewer than 25 per million according to the Modern Chinese Frequency Dictionary (1986). To control for possible influences of familiarity and orthographic variation
(Weekes et al., 1998), character frequency and visual complexity (as measured by the number of strokes in the character) were matched across the homophonic pairs and the semantic pairs.

The stimuli were shown through a LED projector system. The two experimental tasks were the semantic decision task, in which subjects judged whether the two characters they viewed were semantically related, and the homophone decision task, in which subjects decided whether the two characters were homophones. In each trial, a pair of characters were exposed synchronously for $500 \mathrm{~ms}$, one above and one below a fixation crosshair. After the presentation of the two characters, a fixation crosshair was exposed for 1000 ms. Subjects were asked to perform the experimental task as quickly and accurately as possible. They indicated a positive response by pressing the key corre sponding to the index finger of their right (dominant) hand and a negative response by pressing the key corresponding to the index finger of their left (nondominant) hand. A block design was adopted in this study. Semantically related characters (or homophonic characters) were randomized within 24 s blocks comprised of 11 pairs of semantically related characters (or 11 pairs of homophones) and 5 pairs of unrelated characters that served as fillers. In the control scan, the subject maintained fixation on a crosshair. Blocks of 16 pairs of Chinese stimuli (24 s) were separated by $20 \mathrm{~s}$ of fixation. The experiment was conducted in a single run, which consisted of four blocks of semantic decision, four blocks of homophone decision, and eight blocks of crosshair fixation. Presentation of the semantic pairs and homophone pairs was counterbalanced for each subject and randomized across subjects.

\section{Apparatus and Procedure}

The fMRI experiment was performed using a $1.9 \mathrm{~T}$ GE/Elscint Prestige whole-body MRI scanner (GE/ Elscint Ltd., Haifa, Israel) at the Research Imaging Center at UTHSCSA. Prior to fMRI imaging, the subject was visually familiarized with the procedures and the experimental conditions to minimize anxiety and enhance task performance. Following this familiarization, the subject lay supine on the scanning table and was fitted with plastic ear-canal molds. The subject's head was immobilized by a tightly fitting, thermally molded, plastic facial mask that extended from the hairline to the chin (F ox et al., 1985).

A single shot, $\mathrm{T}_{2}{ }^{*}$-weighted gradient-echo echo planar imaging (EPI) sequence was used for the fMRI scans, with the slice thickness $=6 \mathrm{~mm}$, in-plane resolution $=2.9 \mathrm{~mm} \times 2.9 \mathrm{~mm}$, and TR/TE $/ \theta=2000 \mathrm{~ms} / 45$ $\mathrm{ms} / 90^{\circ}$. The field of view was $373 \times 210 \mathrm{~mm}$, and the acquisition matrix was $128 \times 72$. Twenty contiguous axial slices were acquired to cover the whole brain. For each slice, 176 images were acquired with a total scan 
time of $352 \mathrm{~s}$ in a single run. The anatomical MRI was acquired using a $\mathrm{T}_{1}$-weighted, three-dimensional, gradient-echo pulse-sequence. This sequence provided high resolution $(1 \times 1 \times 1 \mathrm{~mm})$ images of the entire brain.

\section{Data Analysis}

We used Matlab (The Math Works, Inc., Natick, MA) and in-house software for image data processing (Xiong et al., 1995), which included corrections for head motion and global MRI signal shift. Skull stripping of the 3-D MRI $\mathrm{T}_{1}$-weighted images was done using Alice software (Perceptive Systems, Inc., Boulder, CO). These images were then spatially normalized to the Talairach brain atlas (Talairach and Tournoux, 1988) using the Convex Hull algorithm (Lancaster et al., 1997; Lancaster et al., 1999).

Functional images were grouped into semantic decision, homophone decision, and fixation groups. I mages from the first $8 \mathrm{~s}$ of each condition were excluded from further functional data processing to minimize the transit effects of hemodynamic responses. Activation maps were calculated by comparing images acquired during each task state (semantic judgment and homophone judgment) with those acquired during the control state (fixation), using a students' group t test. Like the $\mathrm{T}_{1}$-weighted anatomical images, the activation maps were also spatially normalized into Talairach space using the Convex Hull algorithm. The averaged activation maps across the six subjects with a t value of 2.4 ( $P<0.01$ ) were then overlaid on the corresponding $\mathrm{T}_{1}$ images. F or each condition, Talairach coordinates of the center-of-mass and volume $\left(\mathrm{mm}^{3}\right)$ of the activation clusters were determined based on the averaged activation maps. Anatomical labels (lobes, gyri) and Brodmann area (BA) designations were applied automatically using a 3-D electronic brain atlas (Lancaster et al., 1997).

Laterality was evaluated from the functional maps. Activated voxels in regions of interest (ROIs) were used to calculate an asymmetry index (AI) (AI = sum [voxels $(L-R)]$ /sum [voxels $(L+R)$ ]; Binder et al., 1995; Chee et al., 1999a; Desmond et al., 1995). The values of Al range from -1 to +1 , with a negative value indicating right hemispheric dominance and a positive value indicating left hemispheric dominance.

\section{RESULTS}

\section{Behavioral Data}

Average response accuracies and reaction times across subjects were $84 \% / 767 \mathrm{~ms}$ and $88 \% / 762 \mathrm{~ms}$ for semantic and homophone judgments, respectively. The differences were statistically nonsignificant, with both $F$ values less than one. Thus, the two experimental tasks used in this study were regarded as equally difficult (Gabrieli et al., 1998).

\section{Activation data}

Semantic judgment versus fixation. The fMRI images averaged across subjects for the semantic decision vs fixation comparison are shown in Fig. 2. Significant areas of activation in the frontal lobe, as summarized in Table 1, encompassed left middle frontal gyrus (BA 9), bilateral inferior and middle prefrontal gyri (BAs 45/47/11), bilateral frontal pole (BA 10), and precentral (motor) gyri (BAs 6 and 4). Peak activation was located in the left middle frontal cortex (BA 9) with an activation volume of 782 (voxels). To quantify an asymmetry index of functional activation ( $\mathrm{Al}=$ sum [voxels ( $\mathrm{L}-$ R)]/sum [voxels $(L+R)]$ ), we selected the middle and inferior frontal areas as regions of interest (ROIs). Al was 0.62 , indicating a strong left lateralization.

Activations in the parietal lobe were bilateralized. Both left and right superior parietal lobules (BA 7) and inferior or postcentral parietal gyri (BA 40) were significantly activated. In the occipital lobe, activation in left infero-middle gyrus (BA 18) was present. However, activations in the right cortex covering the cuneus, fusiform, and inferior gyrus were stronger than activations in the left cortex, revealing right lateralization $(A I=-0.57)$. Activations in the temporal lobe were localized to the right superior and middle gyri (BA 38). In addition, the left and right sublobar caudate, as well as cerebellum, were involved.

Homophonejudgment versus fixation. The comparison of homophone decision with fixation produced a pattern of brain activation similar to that produced by the comparison of semantic decision and fixation (Fig. 3 and Table 2). Peak activation occurred in left middle frontal gyrus (BA 9). Bilateral inferomiddle prefrontal cortex (BAs 44/45 and 47/10) and left medial prefrontal lobe (BA 11) were active. Activations in these areas were left lateralized, AI $=0.34$. Bilateral precentral (motor) gyri (BA 4/6) were also active. In the parietal cortex, the bilateral superior parietal lobule (BA 7), left postcentral gyrus (BA 3) and right precuneus (BA 39) were involved. In the occipitotemporal regions, significant activations occurred in the left and right cuneus (BA 17/18), the extrastriate cortex covering left inferior gyrus (BA 18), the right fusiform gyrus and lingual gyrus (BAs 18 and 19). The left sublobar and right sublobar caudate, as well as cerebellum, were also activated.

Brain regions active during the homophone decision task but not the meaning decision task relative to fixation were bilateral middle temporal lobes (BAs 21 and 22). Thus, the activation from the occipital cortex extended rostrally to the bilateral temporal gyrus.

\section{DISCUSSION}

We have shown that reading logographic Chinese is characterized by extensive brain activation. Compared 

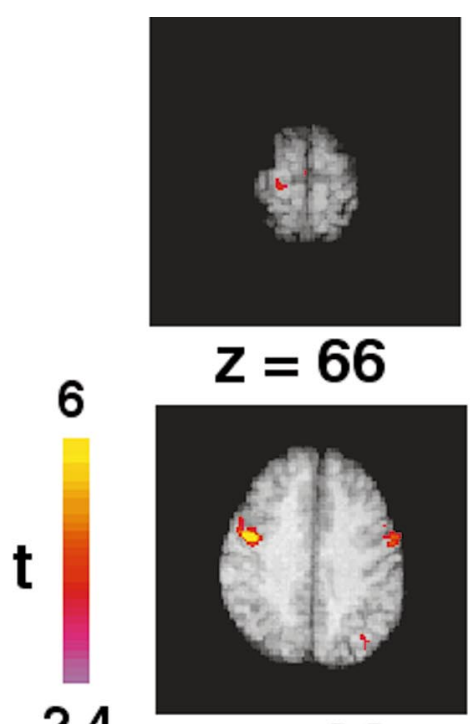

2.4
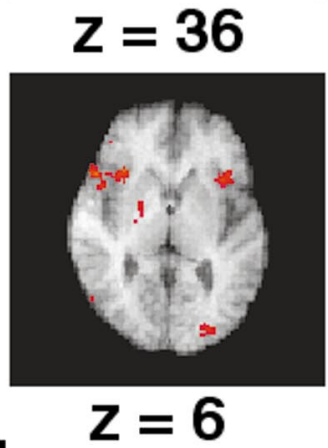

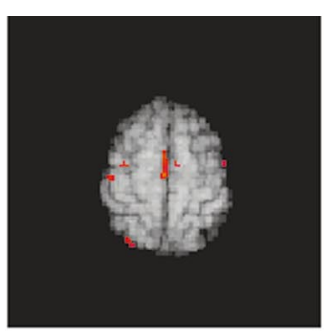

$Z=60$

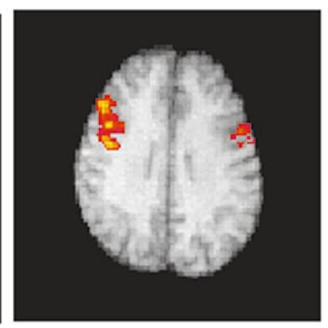

$Z=\mathbf{3 0}$
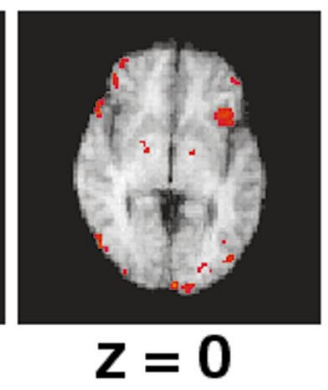

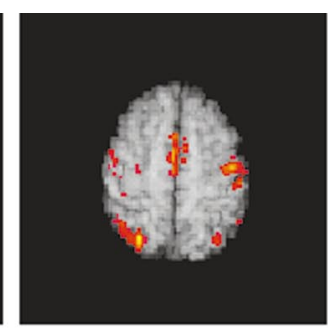

$Z=54$

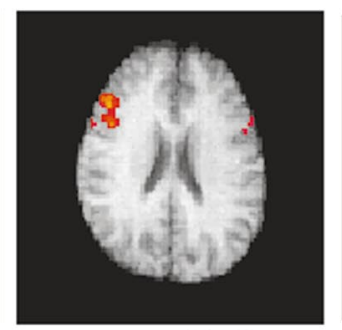

$Z=24$

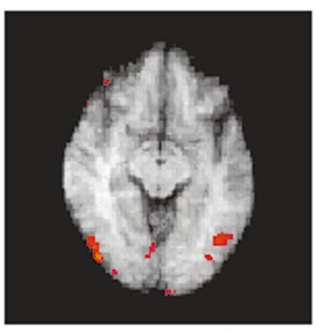

$Z=-6$

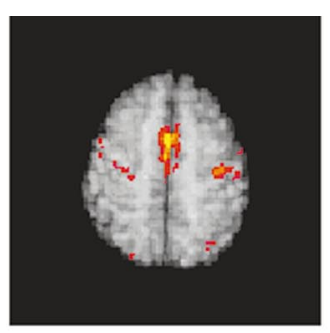

$Z=48$

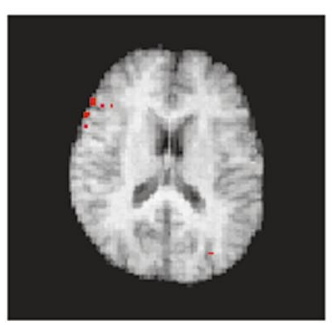

$Z=18$

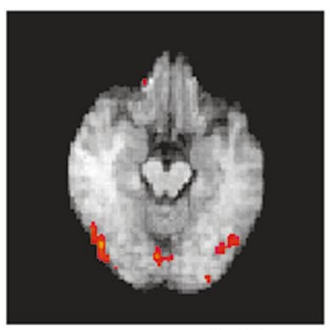

$z=-12$

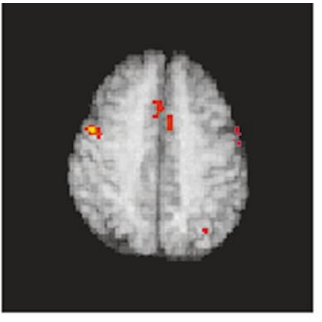

$Z=42$

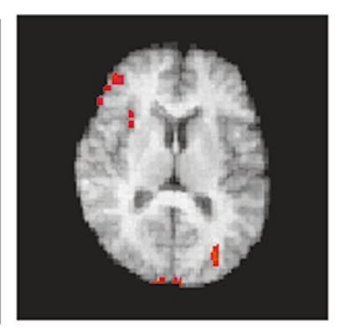

$Z=12$

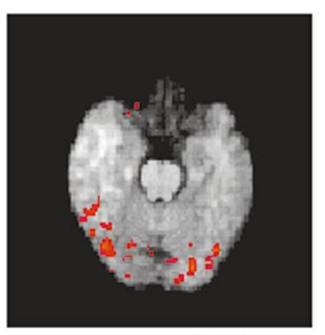

$Z=-18$

$\mathbf{L}$

FIG. 2. Functional maps. Averaged brain activations involved in the semantic decision task compared to fixation. Normalized activation brain maps averaged across six subjects demonstrate the statistically significant activations ( $<<0.01$ ). All of the functional maps (in color) are overlaid on the corresponding $\mathrm{T}_{1}$ images (in gray scale). Planes are axial sections, labeled with the height (mm) relative to the bicommissural line. $L$, the left hemisphere; $R$, the right hemisphere.

to fixation baseline, the distributed neural networks activated by semantic and homophone decisions largely overlapped. Many of the activated areas that contributed to reading Chinese have been implicated in previous work on al phabetic languages. F or instance, a number of studies using alphabetic words demonstrated involvement of ventral occipitotemporal regions, such as the fusiform and lingual gyri (Petersen et al., 1990; Pugh et al., 1997), the left inferior frontal lobe including BAs 44/45 and BA 47 and the neighboring vicinity (Cappa et al., 1998; Demb et al., 1995; Demonet et al., 1992; Fiez et al., 1999; I lles et al., 1999; Mummery et al., 1999; Paulesu et al., 1993; Petersen et al., 1988; Poldrack et al., 1999; Ricci et al., 1999; Vandenberghe et al., 1996; Zatorre et al., 1992), and the temporo- occipitoparietal junction (BA 39/19) (Hodge and Patterson, 1997; Mummery et al., 1998; Price et al., 1997). Cerebellum was also engaged in English word reading, as reported by Petersen et al. (1988), Herbster et al. (1997), and Rumsey et al . (1997), among others. This supports our hypothesis that the function of the cerebellum goes beyond motor coordination (Gao et al., 1996; Liu et al., 1999). The presence of significant activations in these cerebral and cerebellar regions indicates that some brain areas are involved in reading, regardless of the particular language.

However, our results also reveal an important difference in cortical organizations across languages. As can be seen in Figs. 2 and 3, both semantic and homophone decisions showed that peak activation in the processing of logographs was located in the left lateral middle frontal cortex (BA 9), a region above Broca's area. This finding is in line with our previous result from word generation of Chinese characters (Tan et al., 2000) and is also corroborated by the activation result of some of the subjects in the Chinese reading studies by Chee et al. (1999a, 2000). Nevertheless, past investigations with English and other alphabetic languages, whether using similar (Buckner et al., 1995; Klein et al., 1995; Petersen et al., 1988; Thompson-Schill et al., 1999) or 

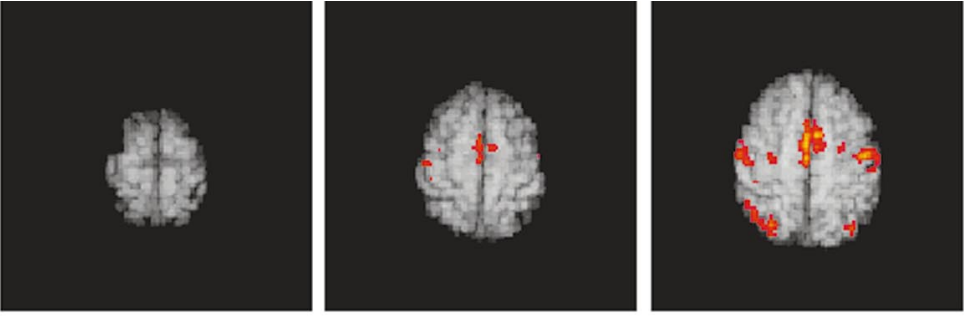

$$
Z=66
$$

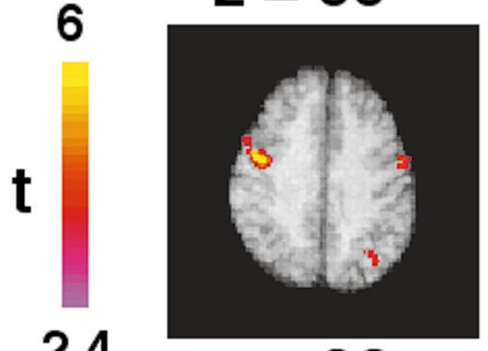

$Z=36$
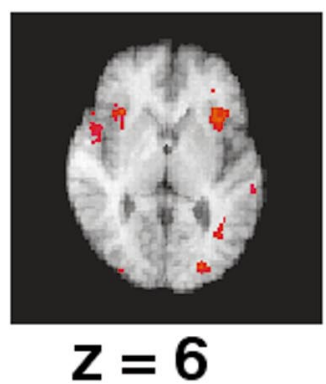
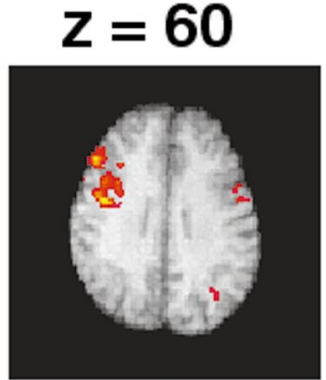

$Z=\mathbf{3 0}$

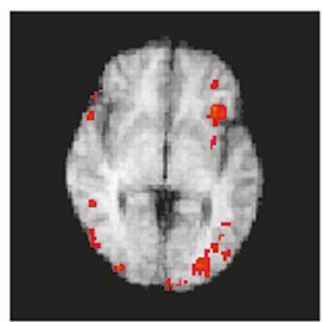

$\mathbf{Z}=\mathbf{0}$

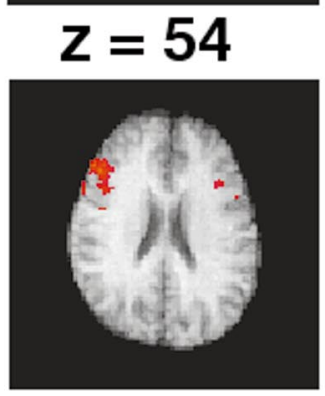

$z=24$

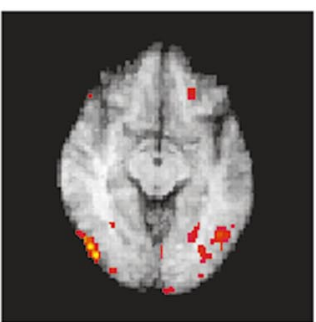

$Z=-6$

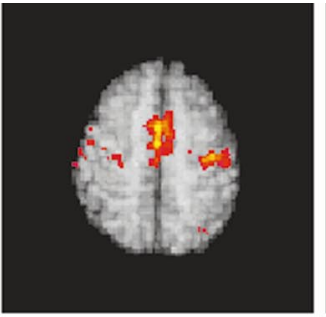

$Z=48$

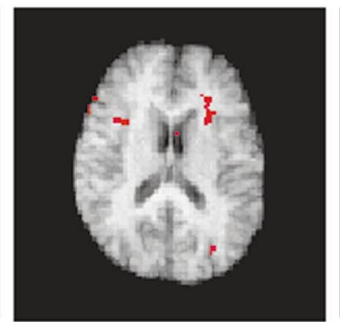

$Z=18$

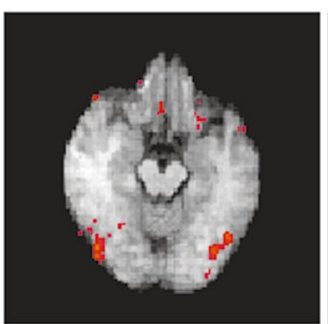

$z=-12$
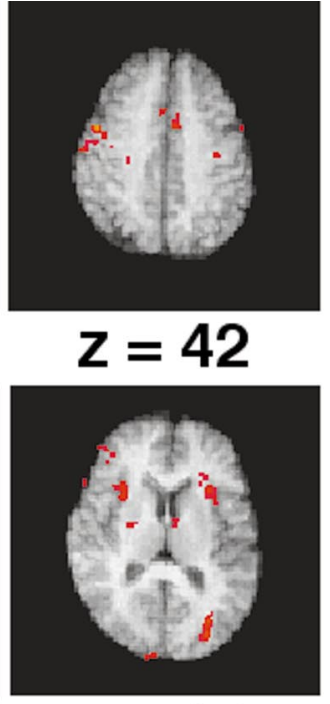

$Z=12$

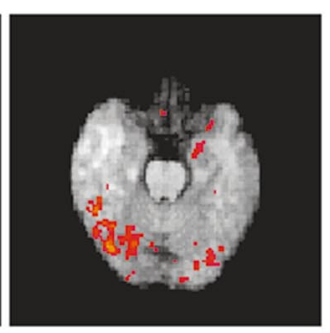

$Z=-18$

FIG. 3. Functional maps. Averaged brain activations involved in the homophone decision task compared to fixation. Normalized activation brain maps averaged across six subjects demonstrate the statistically significant activations ( $P<0.01)$. All of the functional maps (in color) are overlaid on the corresponding $\mathrm{T}_{1}$ images (in gray scale). Planes are axial sections, label ed with the height (mm) relative to the bicommissural line. $L$, the left hemisphere; $R$, the right hemisphere.

different paradigms (Gabrieli et al., 1998; Kim et al., 1997), have not commonly implicated this middorsal prefrontal region in word recognition and reading. Even though this region is noted by several researchers, the reported activation in this area is much weaker for native English readers (Poldrack et al., 1999; Price et al., 1997; Warburton et al., 1996; Wise et al., 1991).

We believe that the extremely strong activation of the left middle frontal gyrus in reading Chinese is associated with the unique square configuration of logographs. Unlike English words that have a linear structure, Chinese logographs comprise a number of strokes that are packed into a square shape according to stroke assembly rules. This requires fine-grained analyses of the visual-spatial locations of the strokes and subcharacter components. Recent data from functional imaging studies suggest that the left middorsal lateral frontal cortex (at BAs 9 and 46) mediates spatial and verbal working memory by which the subject maintains a limited amount of spatial and verbal in- formation in an active state for a brief period of time (0-60 s) (Courtney et al., 1998; McCarthy et al., 1994; Owen et al., 1996; Paulesu et al., 1993). More specifically, this region may act as a central executive system of working memory that is responsible for coordination of cognitive resources (D'Esposito et al., 1995). In our present study, although working memory processes may not be engaged in character decision (Perfetti and Zhang, 1995), the subject indeed needed to coordinate the semantic (or phonological) processing of the Chinese logographs that was explicitly required by the experimental task and the intensive visuospatial processing that was demanded by the visual form of logographs. In this case, the left middle frontal gyrus may be recruited to integrate these two cognitive processes.

Our findings of the heavy involvement of a set of right hemisphere cortical sites converge on the view that reading Chinese logographs demands intensive visual-spatial analysis. The right frontal pole (BA10/ 11), frontal operculum (BA 47/45), dorsolateral frontal 
TABLE 1

Stereotactic Coordinates, t Values, and Corresponding Brodmann Areas (BAs) for Regions Activated Significantly (Meaning J udgment minus Fixation)

\begin{tabular}{|c|c|c|c|c|c|c|c|}
\hline \multirow[b]{2}{*}{ Regions activated } & \multirow[b]{2}{*}{ BA } & \multicolumn{3}{|c|}{ Coordinates } & \multirow{2}{*}{$\begin{array}{l}\text { Volume } \\
\text { (voxels) }\end{array}$} & \multirow[b]{2}{*}{$\mathrm{t}$} & \multirow[b]{2}{*}{$\mathrm{P}$} \\
\hline & & $x$ & Y & z & & & \\
\hline \multicolumn{8}{|l|}{ Frontal } \\
\hline Left middle frontal gyrus & 9 & -45 & 13 & 30 & 782 & 3.72 & 0.0002 \\
\hline \multirow{6}{*}{ Left inferior/middle frontal gyrus } & 45 & -43 & 21 & 6 & 221 & 3.03 & 0.0018 \\
\hline & 45 & -57 & 18 & 21 & 37 & 2.77 & 0.0037 \\
\hline & 11 & -16 & 42 & -17 & 78 & 3.04 & 0.0017 \\
\hline & 11 & -20 & 27 & -19 & 18 & 2.99 & 0.002 \\
\hline & 10 & -40 & 44 & -2 & 30 & 2.89 & 0.0026 \\
\hline & 10 & -36 & 56 & 1 & 15 & 2.78 & 0.0035 \\
\hline \multirow[t]{3}{*}{ Left precentral gyrus } & 6 & -29 & -16 & 55 & 44 & 2.79 & 0.0035 \\
\hline & 4 & -46 & -9 & 53 & 46 & 2.78 & 0.0036 \\
\hline & 4 & -35 & -13 & 47 & 19 & 2.83 & 0.0032 \\
\hline \multirow{3}{*}{ Right inferior/middle frontal gyrus } & 47 & 38 & 19 & 2 & 168 & 3.07 & 0.0016 \\
\hline & $9 / 44$ & 51 & 9 & 29 & 101 & 2.89 & 0.0026 \\
\hline & 10 & 45 & 44 & 0 & 10 & 2.62 & 0.0055 \\
\hline \multirow[t]{4}{*}{ Right precentral/medial gyrus } & 6 & 0 & -1 & 50 & 588 & 3.54 & 0.0004 \\
\hline & 6 & 55 & -1 & 35 & 104 & 3.00 & 0.002 \\
\hline & 4 & 40 & -17 & 52 & 260 & 3.37 & 0.0006 \\
\hline & 4 & 51 & -4 & 46 & 11 & 2.70 & 0.0044 \\
\hline \multicolumn{8}{|l|}{ Temporal } \\
\hline \multirow[t]{2}{*}{ Right superior/middle gyrus } & 38 & 27 & 14 & -37 & 27 & 2.77 & 0.0037 \\
\hline & 38 & 41 & 5 & -35 & 16 & 2.74 & 0.004 \\
\hline \multicolumn{8}{|l|}{ Parietal } \\
\hline Left superior parietal lobule & 7 & -30 & -64 & 54 & 181 & 3.24 & 0.001 \\
\hline \multirow{2}{*}{ Left postcentral gyrus } & 3 & -40 & -21 & 59 & 22 & 2.78 & 0.0036 \\
\hline & 40 & -37 & -33 & 56 & 10 & 2.87 & 0.0028 \\
\hline Right superior parietal lobule & 7 & 31 & -67 & 46 & 79 & 2.77 & 0.0037 \\
\hline Right inferior parietal lobule & 40 & 44 & -48 & 52 & 29 & 2.72 & 0.0043 \\
\hline \multicolumn{8}{|l|}{ Occipital } \\
\hline \multirow[t]{2}{*}{ Left middle/inferior gyrus } & 18 & -11 & -95 & 12 & 18 & 2.88 & 0.0028 \\
\hline & 18 & -34 & -87 & 0 & 16 & 2.68 & 0.0046 \\
\hline Right cuneus & 17 & 8 & -97 & -1 & 82 & 2.91 & 0.0025 \\
\hline Right inferior occipital gyrus & 19 & 39 & -78 & -3 & 30 & 2.81 & 0.0034 \\
\hline Right fusiform gyrus & 18 & 28 & -91 & -13 & 12 & 3.13 & 0.0013 \\
\hline \multicolumn{8}{|l|}{ Other areas } \\
\hline Left sublobar caudate & & -21 & -3 & 4 & 57 & 2.77 & 0.0037 \\
\hline Right sublobar caudate & & 15 & -5 & 2 & 13 & 2.81 & 0.0033 \\
\hline \multicolumn{8}{|l|}{ Cerebellum } \\
\hline Left declive & & -44 & -59 & -20 & 975 & 3.45 & 0.0005 \\
\hline Right uvula & & 17 & -72 & -23 & 1502 & 3.12 & 0.0010 \\
\hline Right cerebellar tonsil & & 44 & -47 & -31 & 54 & 2.84 & 0.0031 \\
\hline Right anterior cerebellum & & 19 & -38 & -28 & 17 & 2.77 & 0.0037 \\
\hline Right tuber & & 50 & -59 & -29 & 14 & 2.95 & 0.0022 \\
\hline
\end{tabular}

Note. The $t$ values presented in this table are the mean $t$ values of a cluster.

gyrus (BA 9/44), and the superior and inferior parietal lobules (BAs 7, 40/39) mediated semantic and homophonic judgments. These areas were not implicated in most of the studies with al phabets as well (reviewed by Price, 1997, and Fiez and Petersen, 1998; but see a recent PET study by MacLeod et al., 1998). However, it is well known that these right prefrontal regions service episodic memory processes by which one retrieves the spatial relation of perceived objects (Kapur et al., 1995; Lepage et al., 2000; Haxby et al., 1996; Nyberg et al., 1996; Schacter et al., 1995; Squire and Zola, 1998; Tulving et al., 1994). I $n$ addition, the right BAs 7 and 40/39 are routinely activated in spatial working memory tasks (Courtney et al., 1998; Haxby et al., 1995; Heinze et al., 1994; J onides et al., 1993; McCarthy et al., 1994; Smith and J onides, 1998). Based on these previous studies, it is reasonable to assume that the right frontal and parietal regions are involved in perceiving the spatial locations of the strokes and the processes of stroke combinations. 
TABLE 2

Stereotactic Coordinates, t Values, and Corresponding Brodmann Areas (BAs) for Regions Activated Significantly (Homophone J udgment minus Fixation)

\begin{tabular}{|c|c|c|c|c|c|c|c|}
\hline \multirow[b]{2}{*}{ Regions activated } & \multirow[b]{2}{*}{ BA } & \multicolumn{3}{|c|}{ Coordinates } & \multirow{2}{*}{$\begin{array}{l}\text { Volume } \\
\text { (voxels) }\end{array}$} & \multirow[b]{2}{*}{$\mathrm{t}$} & \multirow[b]{2}{*}{$P$} \\
\hline & & $x$ & Y & z & & & \\
\hline \multicolumn{8}{|l|}{ Frontal } \\
\hline \multirow[t]{3}{*}{ Left middle frontal gyrus } & 9 & -43 & 13 & 27 & 952 & 3.42 & 0.0006 \\
\hline & 9 & -32 & 24 & 30 & 11 & 2.99 & 0.0020 \\
\hline & 10 & -41 & 44 & 12 & 22 & 2.60 & 0.0058 \\
\hline \multirow{3}{*}{ Left inferior frontal gyrus } & 45 & -58 & 19 & 21 & 38 & 2.98 & 0.0021 \\
\hline & 47 & -47 & 34 & -11 & 16 & 2.94 & 0.0023 \\
\hline & 47 & -50 & 31 & -1 & 12 & 2.77 & 0.0037 \\
\hline Left medial frontal gyrus & 11 & -17 & 41 & -19 & 12 & 2.77 & 0.0037 \\
\hline \multirow[t]{2}{*}{ Left precentral gyrus } & 4 & -29 & -16 & 50 & 80 & 2.81 & 0.0033 \\
\hline & 4 & -47 & -14 & 53 & 178 & 2.91 & 0.0025 \\
\hline \multirow[t]{5}{*}{ Right inferior/middle frontal gyrus } & 45 & 33 & 20 & 7 & 400 & 3.08 & 0.0016 \\
\hline & 9/44 & 50 & 9 & 29 & 22 & 2.85 & 0.0030 \\
\hline & 47 & 27 & 15 & -16 & 71 & 2.74 & 0.0040 \\
\hline & 47 & 23 & 33 & -7 & 24 & 2.68 & 0.0047 \\
\hline & 11 & 36 & 37 & -14 & 10 & 2.61 & 0.0056 \\
\hline \multirow{2}{*}{ Right medial/middle frontal gyrus } & 6 & 1 & -3 & 51 & 777 & 3.49 & 0.0004 \\
\hline & 6 & 23 & -10 & 55 & 24 & 2.78 & 0.0036 \\
\hline \multirow[t]{2}{*}{ Right precentral gyrus } & 4 & 40 & -17 & 51 & 307 & 3.39 & 0.0006 \\
\hline & 6 & 54 & -1 & 35 & 90 & 2.90 & 0.0026 \\
\hline \multicolumn{8}{|l|}{ Temporal } \\
\hline Left middle temporal gyrus & 21 & -52 & -42 & 0 & 19 & 2.81 & 0.0033 \\
\hline \multirow[t]{4}{*}{ Right superior/middle gyrus } & 22 & 61 & -31 & 7 & 10 & 2.61 & 0.0056 \\
\hline & 38 & 27 & 15 & -36 & 35 & 2.77 & 0.0037 \\
\hline & 38 & 36 & 8 & -38 & 24 & 2.80 & 0.0034 \\
\hline & 38 & 54 & 11 & -14 & 15 & 2.73 & 0.0041 \\
\hline \multicolumn{8}{|l|}{ Parietal } \\
\hline Left superior parietal lobule & 7 & -32 & -61 & 54 & 124 & 2.98 & 0.0020 \\
\hline Left postcentral gyrus & 3 & -37 & -32 & 57 & 17 & 3.00 & 0.0019 \\
\hline Right superior parietal lobule & 7 & 30 & -66 & 52 & 35 & 2.94 & 0.0023 \\
\hline Right precuneus (PCu) & 39 & 34 & -66 & 34 & 66 & 2.81 & 0.0033 \\
\hline \multicolumn{8}{|l|}{ Occipital } \\
\hline Left inferior gyrus & 18 & -33 & -87 & -1 & 51 & 3.07 & 0.0016 \\
\hline Left cuneus & 18 & -12 & -97 & 13 & 21 & 2.84 & 0.0030 \\
\hline Right cuneus & 17 & 6 & -98 & -2 & 46 & 2.79 & 0.0035 \\
\hline \multirow{2}{*}{ Right fusiform gyrus } & 18 & 31 & -88 & -13 & 10 & 2.57 & 0.0063 \\
\hline & 19 & 26 & -59 & -7 & 35 & 2.76 & 0.0038 \\
\hline Right lingual gyrus & 19 & 3 & -72 & -5 & 18 & 2.55 & 0.0066 \\
\hline \multicolumn{8}{|l|}{ Other areas } \\
\hline \multicolumn{2}{|l|}{ Left sublobar caudate } & -26 & -5 & 12 & 16 & 2.67 & 0.0048 \\
\hline \multicolumn{2}{|l|}{ Right sublobar caudate } & 4 & 1 & 14 & 38 & 2.72 & 0.0043 \\
\hline \multicolumn{2}{|l|}{ Right sublobar claustrum } & 33 & 0 & 1 & 13 & 2.61 & 0.0056 \\
\hline Cerebellum & & & & & & & \\
\hline Left declive & & -6 & -66 & -18 & 2915 & 3.17 & 0.0012 \\
\hline Right cerebellar tonsil & & 42 & -46 & -33 & 49 & 2.67 & 0.0048 \\
\hline
\end{tabular}

Note. The $t$ values presented in this table are the mean $t$ values of a cluster.

While activations in the occipital cortex were bilateral, the right side was dominant over the left side (AI was -0.57 in the semantic task vs fixation comparison and -0.204 in the homophone task vs fixation comparison). As the right occipital cortex is associated with the spatial recognition of visual symbols (e.g., Clark et al., 1996; Shen et al., 1999), its strong activity seen in this experiment can, again, be attributed to the visual properties of Chinese characters. The involvement of the bilateral visual cortex and the superior and inferior parietal lobe suggests the role of a dorsal pathway responsible for spatial localization in reading Chinese characters. Through the dorsal pathway, visual processing that originates from the striate cortex reaches the posterior parietal cortex (Ungerleider and Mishkin, 1982).

To summarize, our results suggest that reading logographic Chinese is serviced by a distributed neural system. As in English word reading and recognition, the left inferior prefrontal cortex is active in processing 
Chinese characters. Peak activation associated with reading Chinese, however, is located in the left middle lateral frontal region, an area that mediates the coordination of cognitive resources. We hypothesize that in reading Chinese logographs, the left middle frontal cortex is recruited to coordinate and integrate the intensive visuospatial analysis demanded by logographs' unique square configuration and the semantic (or phonological) analysis required by the present experimental tasks. Our finding of the involvement of the right prefrontal and parietal areas lends strong support to the assumption that the visual-spatial attributes of Chinese script require a fine-grained analysis during reading and recognition.

\section{CONCLUSIONS}

We have demonstrated that, when normal Chinese adults read logographic characters, a distributed network of brain areas was activated. Compared to fixation baseline, peak activations provoked by semantic as well as homophony decisions were found in the left middle frontal gyrus (BA 9). The left inferior frontal cortex also mediated the processing of Chinese logographs. There were more right hemispheric regions (e.g., BAs 47/45, 7, 40/39, and the right visual system) involved in reading Chinese compared with reading English. This can be explained by the fact that the Chinese logographs' square shape requires a particular analysis of spatial information of various strokes which make up the logographic character. Our explanation agrees with the notion that some languages have special processing requirements (Neville et al., 1998; Paulesu et al., 2000). We infer that the left middle frontal area (BA 9) coordinates and integrates semantic (phonological) and visuospatial analyses of Chinese logographs. In a nutshell, our experiment has implicated brain regions common to both logographic and alphabetic languages as well as brain regions specialized in processing and representing logographic Chinese.

\section{ACKN O WLEDG MENTS}

We thank Ching-Mei Feng, Lisa Nickerson, Yonglin Pu, and J inhu Xiong for technical assistance, and two anonymous reviewers for insightful comments on an early version of the paper. This research was supported by Hong Kong Research Grants Council (RGC) grant (10202359).

\section{REFERENCES}

Binder, J . R., Swanson, S. J ., Hammeke, T. A., Morris, G. L., Mueller, W. M., Fisher, M., Frost, J . A., and Rao, S. M. 1995. Determination of language dominance with functional MRI: A comparison with the Wada test. Hum. Brain Mapp. 1: 235.

Bookheimer, S. Y., Zeffiro, T. A., Blaxton, T., Gaillard, W., and Theodore, W. 1995. Regional cerebral blood flow during object naming and word reading. Hum. Brain Mapp. 3: 93-106.
Brunswick, N., McCrory, E., Price, C. J ., Frith, C. D., and Frith, U. 1999. Explicit and implicit processing of words and pseudowords by adult developmental dyslexics. Brain 122: 1901-1917.

Buckner, R. L., and Petersen, S. E. 1996. What does neuroimaging tell us about the role of prefrontal cortex in memory retrieval? Semin. Neurosci. 8: 47-55.

Buckner, R. L., Raichle, M. E., and Petersen, S. E. 1995. Dissociation of prefrontal cortical areas across different speech production tasks and gender groups. J . Neurophysiol. 74: 2163-2173.

Caplan, D., Alpert, N., Waters, G., and Olivieri, A. 2000. Activation of Broca's Area by syntactic processing under conditions of concurrent articulation. Hum. Brain Mapp. 9: 65-71.

Cappa, S. F., Perani, D., Schnur, T., Tettamanti, M., and Fazio, F. 1998. The effects of semantic category and knowledge type on lexical-semantic access: A PET study. Neurol mage 8: 350-359.

Chee, M., Tan, E., and Thiel, T. 1999a. Mandarin and English single word processing studies with functional magnetic resonance imaging. J . Neurosci. 19: 3050-3056.

Chee, M., Caplan, D., Soon, C. S., Sriram, N., Tan, E., Thiel, T., and Weekes, B. 1999b. Processing of visually presented sentences in Mandarin and English studied with fMRI. Neuron 23: 127-137.

Chee, M., Weekes, B., Lee, K. M., Soon, C. S., Schreiber, A., Hoon, J.J., and Chee, M. 2000. Overlap and dissociation of semantic processing of Chinese characters, English words, and pictures: Evidence from fMRI. Neurol mage 12: 392- 403.

Cheng, C. M., and Yang, M. J . 1986. Lateralization in the visual perception of Chinese characters and words. Brain Lang. 36: 669689.

Clark, V. P., Keil, K., Maisog, J . M., Courtney, S., Ungerleider, L. G., and Haxby, J . V. 1996. Functional magnetic resonance imaging of human visual cortex during face matching: A comparison with positron emission tomography. Neurol mage 4: 1-15.

Courtney, S. M., Petit, L., Maisog, J. M., Ungerleider, L. G., and Haxby, J . V. 1998. An area specialized for spatial working memory in human frontal cortex. Science 279: 1347-1351.

Dehaene, S., Dupoux, E., Mehler, J ., Cohen, L., Paulesu, E., Perani, D., van de Moortele, P., Lehericy, S., and Le Bihan, D. 1997. Anatomical variability in the cortical representation of first and second language. NeuroReport 8: 3809-3815.

Demb, J . B., Desmond, J . E., Wagner, A. D., Vaidya, C. T., Glover, G. H., and Gabrieli, J . D. E. 1995. Semantic encoding and retrieval in the left inferior prefrontal cortex: A functional MRI study of task difficulty and process specificity. J . Neurosci. 15: 5870-5878.

Demonet, J . F., Chollet, F., Ramsay, S., Cardebat, D., Nespoulous, J . N., Wise, R., Rascol, A., and Frackowiak, R. 1992. The anatomy of phonological and semantic processing in normal subjects. Brain 115: 1753-1768.

Desmond, J . E., Sum, J . M., Wagner, A. D., Demb, J . B., Shear, P. K., Glove, G. H., Gabrieli, J . D. E., and Morrell, M.J . 1995. Functional MRI measurement of language lateralization in Wada-tested patients. Brain 118: 1411-1419.

D’E sposito, M., Detre, J . A., Alsop, D. C., Shin, R. K., Atlas, S., and Grossman, M. 1995. The neural basis of the central executive system of working memory. Nature 378: 279-281.

Fang, S. P. 1997. Morphological properties and the Chinese character-word difference in laterality patterns. J. Exp. Psychol. Hum. Percep. Perform. 23: 1439-1453.

Fiez, J. A., and Petersen, S. E. 1998. Neuroimaging studies of word reading. Proc. Natl. Acad. Sci. USA 95: 914-921.

Fiez, J . A., Balota, D., Raichle, M., and Petersen, S. 1999. Effects of lexicality, frequency, and spelling-to-sound consistency on the functional anatomy of reading. Neuron 24: 205-218. 
Fox, P. T., Perlmutter, J . S., and Raichle, M. E. 1985. A stereotactic method of anatomical localization for postron emission tomography. J . Comput. Assist. Tomogr. 9: 141-153.

Fujimaki, N., Miyauchi, S., Putz, B., Sasaki, Y., Takino, R., Sakai, K., and Tamada, T. 1999. Functional magnetic resonance imaging of neural activity related to orthographic, phonological, and semantic judgments of visually presented characters and words. Hum. Brain Mapp. 8: 44-59.

Gabrieli, J . D. E., Desmond, J . E., Demb, J . B., Wagner, A. D., Stone, M. V., Vaidya, C. J ., and Glove, G. H. 1996. Functional magnetic resonance imaging of semantic memory processes in the frontal lobes. Psychol. Sci. 7: 278-283.

Gabrieli, J . D., Poldrack, R. A., and Desmond, J . E. 1998. The role of left prefrontal cortex in language and memory. Proc. Natl. Acad. Sci. USA 95: 906-913.

Gandour, J ., Wong, D., Hsieh, L., Weinzapfel, B., Van Lancker, D., and Hutchins, G. D. 2000. A crosslinguistic PET study of tone perception. J . Cogn. Neurosci. 12: 207-222.

Gao, J .-H., Parsons, L., Bower, J . M., Xiong, J ., Li, J ., and Fox, P. T. 1996. Cerebellum implicated in sensory acquisition and discrimination rather than motor control. Science 272: 545-547.

Hagoort, P., Indefrey, P., Brown, C., Herzog, H., Steinmetz, H., and Seiz, R. 1999. The neural circuity involved in the reading of German words and pseudowords: A PET study. J . Cogn. Neurosci. 11: 383-398.

Haxby, J ., Ungerleider, L., Horwitz, B., Rapoport, S., and Grady, C. 1995. Hemispheric difference in neural systems for face working memory: A PET-rCBF study. Hum. Brain Mapp. 3: 68-82.

Haxby, J. V., Ungerleider, L. G., Horwitz, B., Maisog, J. M., Rapoport, S. I., and Grady, C. L. 1996. Face encoding and recognition in the human brain. Proc. Natl. Acad. Sci. USA 93: 922-927.

Heinze, H. J ., Mangun, G., Burchet, W., Hinrichs, H., Scholz, M., Munte, T., Gos, A., Scherg, M., J ohannes, S., Hundeshagen, H., et al. 1994. Combined spatial and temporal imaging of brain activity during visual selective attention in humans. Nature 372: 543-546.

Herbster, A. N., Mintun, M. A., Nebes, R. D., and Becker, J . T. 1997. Regional cerebral blood-flow during word and non-word reading. Hum. Brain Mapp. 5: 84-92.

Howard, D., Patterson, K., Wise, R., Brown, W. D., Friston, K., Weiller, C., and Frackowiak, R. 1992. The cortical localization of the lexicons. Brain 115: 1769-1782.

Hodge, J. R., and Patterson, K. 1997. Semantic memory disorders. Trends. Cogn. Sci. 1: 68-72.

Illes, J., Francis, W. S., Desmond, J. E., Gabrieli, J ., Glover, G., Poldrack, R., Lee, C., and Wagner, A. 1999. Convergent cortical representation of semantic processing in bilinguals. Brain and Lang. 70: 347-363.

J onides, J ., Smith, E. E., Poeppe, R. A., Awh, E., Minoshima, S., and Mintun, M. A. 1993. Spatial working memory in humans as revealed by PET. Nature 363: 623-625.

J ust, M., Carpenter, P. A., and Varma, S. 1999. Computation modeling of high-level cognition and brain function. Hum. Brain Mapp. 8: $128-136$.

Kapur, N., Friston, K. J ., Yong, A., and Frith, C. D. 1995. Activation of human hippocampal formation during memory for faces: A PET study. Cortex 31: 99-108.

Kim, K., Relkin, N., Lee, K., and Hirsch, J . 1997. Distinct cortical areas associated with native and second languages. Nature 388: 171-174.

Klein, D., Milner, B., Zatorre, R., Meyer, E., and Evans, A. 1995. The neural substrates underlying word generation: A bilingual functional-imaging study. Proc. Natl. Acad. Sci. USA 92: 2899-2903.
Klein, D., Zatorre, R., Milner, B., Meyer, E., and Evans, A. 1994. Left putaminal activation when speaking a second language: Evidence from PET. NeuroReport 5: 2295-2297.

Lancaster, J . L., Fox, P. T., Downs, H., Nickerson, D. S., Hander, T. A., Mallah, M. E., Kochunov, P. V., and Zamarripa, K. 1999. Global spatial normalization of human brain using convex halls. J . Nucl. Med. 40: 942-955.

Lancaster, J . L., Rainey, L. H., Summerlin, J . L., Freitas, C. S., Fox, P. T., Toga, A. W., and Mazziotta, J . C. 1997. Automated labeling of the human brain: A preliminary report on the development and evaluation of a forward-transform method. Hum. Brain Mapp. 5: 238-242.

Lepage, M., Ghaffar, O., Nyberg, L., and Tulving, E. 2000. Prefrontal cortex and episodic memory retrieval mode. Proc. Natl. Acad. Sci. USA 97: 506-511.

Liu, Y., Gao, J . H., Liotti, M., Pu, Y., and Fox, P. T. 1999. Temporal dissociation of parallel processing in the human subcortical outputs. Nature 400: 364-367.

MacLeod, A., Buckner, R., Miezin, F., Petersen, S., and Raichle, M. 1998. Right anterior prefrontal cortex activation during semantic monitoring and working memory. Neurol mage 7: 41- 48.

McCarthy, G., Blamire, A. M., Puce, A., Nobre, A., Bloch, G., Hyder, F., Goldman-Rakic, P., and Shulman, R. G. 1994. Functional MR imaging of human prefrontal cortex activation during a spatial working memory task. Proc. Natl. Acad. Sci. USA 91: 8690-8694.

Mazoyer, B., Dehaene, S., Tzourio, N., Frak, V., Murayama, N., Cohen, L., Levrier, O., Salamon, G., Syrota, A., and Mehler, J. 1993. The cortical representation of speech. J . Cogn. Neurosci. 5: 467- 479 .

More, C. J ., and Price, C. J . 1999. Three distinct ventral occipototemporal regions for reading and object naming. Neurol mage 10: 181-192.

Mummery, C., Shallice, T., and Price, C. J . 1999. Dual-process model in semantic priming: A functional imaging perspective. Neurol mage 9: 516-525.

Mummery, C. J ., Patterson, K., Hodge, J . R., and Price, C. J . 1998. Functional neuroanatomy of the semantic system: divisible by what? J . Cogn. Neurosci. 10: 766-777.

Naeser, M. A., and Chan, S. W. 1980. Case study of a Chinese aphasic with the Boston dianostic aphasia exam. Neuropsychologia 18: 389-410.

Neville, H., Bavelier, D., Corina, D., Rauschecker, J., Karni, A., Lalwani, A., Braun, A., Clark, V., J ezzard, P., and Turner, R. 1998. Cerebral organization for language in deaf and hearing subjects: Biological constraints and effects of experience. Proc. Natl. Acad. Sci. USA 95: 922-929.

Nyberg, L., Mcl ntosh, A. R., Cabeza, R., Habib, R., Houle, S., and Tulving, E. 1996. General and specific brain regions involved in encoding and retrieval of events: what, where, and when. Proc. Natl. Acad. Sci. USA 93: 11280-11285.

Owen, A. M., Doyon, J ., Petrides, M., and Evans, A. C. 1996. Planning and spatial-working memory: A positron emission tomography study in humans. Eur. J . Neurosci. 8: 353-364.

Paulesu, E., Frith, C. D., and Frackowiak, R. S. J . 1993. The neural correlates of the verbal component of working memory. Nature 362: 342-345.

Paulesu, E., McCrory, E., Fazio, F., Menoncello, L., Brunswick, N., Cappa, S. F., Cotelli, M., Cossu, G., Corte, F., Lorusso, M., Pesenti, S., Gallagher, A., Perani, D., Price, C., Frith, C. D., and Frith, U. 2000. A cultural effect on brian function. Nature Neurosci. 3: 91-96.

Perani, D., Dehaene, S, Grassi, F., Cohen, L., Cappa, S., Dupoux, E., Fazio, F., and Mehler, J. 1996. Brain processing of native and foreign languages. NeuroReport 7: 2439-2444. 
Perfetti, C. A., and Zhang, S. 1995. Very early phonological activation in Chinese reading. J . Exp. Psychol. Learn. Mem. Cogn. 21: 24-33.

Petersen, S. E., Fox, P. T., Posner, M. I., Mintun, M., and Raichle, M. E. 1988. Positron emission tomographic studies of cortical anatomy of single-word processing. Nature 331: 585-589.

Petersen, S. E., Fox, P. T., Snyder, A. Z., and Raichle, M. E. 1990. Activation of extrastriate and frontal cortical areas by visual words and word-like stimuli. Science 249: 1041-1044.

Plaut, D., McClelland, J ., Seidenberg, M., and Patterson, K. 1996. Understanding normal and impaired word reading: Computational principles in quasi-regular domains. Psych. Rev. 103: 56115.

Poldrack, R. A., Wagner, A. D., Prull, M. W., Desmond, J . E., Glover, G. H., and Gabrieli, J. D. E. 1999. Functional specialization for semantic and phonological processing in the left inferioir prefrontal cortex. Neurol mage 10: 15-35.

Price, C. J . 1997. Functional anatomy of reading. In Human Brain Function (Frackowiak, R. S. J ., Friston, K. J ., Frith, C. D., Dolan, R. J ., and Mazziotta, J. C., Eds.), pp. 301-328. Academic Press, San Diego.

Price, C. J ., Wise, R. J ., Watson, J . D., Patterson, K., Howard, D., and Frackowiak, R. S. 1994. Brain activity during reading: The effects of exposure duration and task. Brain 117: 1255-1269.

Price, C. J ., More, C. J ., Humphreys, G. W., and Wise, R. S. J . 1997. Segregating semantic from phonological processes during reading. J. Cogn. Neurosci. 9: 727-733.

Pugh, K. R., Shaywitz, B. A., Shaywitz, S. E., Shankweiler, D. P., Katch, L., Fletcher, J . M., Skudlarski, P., Fulbright, R. K., Constable, R. T., Bronen, R. A., et al. 1997. Predicting reading performance from neuroimaging profiles: The cerebral basis of phonological effects in printed word identification. J. Exp. Psychol. Hum. Percept. Perform. 23: 299-318.

Ricci, P. T., Zelkowicz, B. J ., Nebes, R. D., Meltzer, C. C., Mintun, M. A., and Becker, J . T. 1999. Functional neuroanatomy of semantic memory: Recognition of semantic associations. Neurol mage 9: 88-96.

Roskies, A. L., Fiez, J. E., Balota, D. A., Ojemann, J. G., Raichle, M. E., and Petersen, S. E. 1996. PET studies of semantic analysis. Soc. Neurosci. Abstr. 22: 1110.

Rumsey, J. Horwitz, B., Donohue, C., Nace, K., Maisog, J ., and Andreason, P. 1997. Phonological and orthographic components of word recognition: A PET-rCBF study. Brain 119: 739-759.

Schacter, D., Reiman, E., Uecker, A., Polster, M., Yun, L., and Cooper, L. A. 1995. Brain regions associated with retrieval of structurally coherent visual information. Nature 376: 587-590.

Shaywitz, B. A., Pugh, K. R., Constable, T., Shaywitz, S. E., Bronen, R. A., Fulbright, R. K., et al. 1996. Location of semantic processing using functional magnetic resonance imaging. Hum. Brain Mapp. 2: 149-158.

Shen, L., Hu, X., Yacoub, E., and Ugurbil, K. 1999. Neural correlates of visual form and visual spatial processing. Hum. Brain Mapp. 8: 60-71.

Smith, E. E., and J onides, J . 1998. Neuroimaging analyses of human working memory. Proc. Natl. Acad. Sci. USA 95: 12061-12068.

Snyder, P. J ., and Harris, L. J . 1993. Handedness, Sex and familiar sinistrality effects on spatial tasks. Cortex 29: 115-134.

Spinks, J. A., Liu, Y., Perfetti, C. A., and Tan, L. H. 2000. Reading Chinese characters for meaning: The role of phonological information. Cognition 76: B1-B11.
Squire, L. R., and Zola, S. M. 1998. Episodic memory, semantic memory, and amnesia. Hippocampus 8: 205-211.

Talairach, J ., and Tournoux, P. 1988. Co-planar Stereotactic Atlas of the Human Brain. Theime Medical, New York.

Tan, L. H., and Perfetti, C. A. 1998. Phonological codes as early sources of constraint in Chinese word identification: A review of current discoveries and theoretical accounts. Read. Writ. 10: 165200.

Tan, L. H., Spinks, J . A., Gao, J . H., Liu, A., Perfetti, C. A., Xiong, J ., Pu, Y., Liu, Y., Stofer, K. A., and Fox, P. T. 2000. Brain activation in the processing of Chinese characters and words: A functional MRI study. Hum. Brain Mapp. 10: 27-39.

Tan, L. H., Feng, C. M., Fox, P. T., and Gao, J. H. 2001. An fMRI study with written Chinese. NeuroReport 12: 83- 88.

Thompson-Schill, S. L., D’E sposito, M., and Kan, I. P. 1999. Effects of repetition and competition on activity in left prefrontal cortex during word generation. Neuron 23: 513-522.

Tulving, E., Markowitsch, H. J ., Kapur, S., Habib, R., and Houle, S. 1994. Novelty encoding networks in the human brain: Positron emission tomography data. NeuroReport 5: 2525-2528.

Tzeng, O., Hung, D., Cotton, B., and Wang, W. 1979. Visual lateralization effect in reading Chinese characters. Nature 282: 499-501.

Uchida, I., Kikyo, H., Nakajima, K., Konishi, S., Sekihara, K., and Miyashita, Y. 1999. Activation of lateral extrastriate areas during orthographic processing of J apanese characters studied with fMRI. Neurol mage 9: 208-215.

Ungerleider, L. G., and Mishkin, M. 1982. Two cortical pathways. In Analysis of Visual Behavior (Ingle, D. J., Goodale, M. A., and Mansfield, R. J . W., Eds.), pp. 549-586. MIT Press, Cambridge.

Vandenberghe, R., Price, C. J ., Wise, R., J osephs, O., and Frackowiak, R. S. J . 1996. Functional anatomy of a common semantic system for words and pictures. Nature 383: 254-256.

Wagner, A. D., Desmond, J. E., Demb, J. B., Glover, G. H., and Gabrieli, J . D. E. 1997. Semantic repetition priming for verbal and pictorial knowledge: A functional MRI study of left inferior prefrontal cortex. J . Cogn. Neurosci. 9: 714-726.

Warburton, E., Wise, R. J ., Price, C. J ., Weiller, C., Hadar, U., Ramsay, S., and Frackowiak, R. S. 1996. Noun and verb retrieval by normal subjects. Studies with PET. Brain 119: 159-179.

Weber-Fox, C., and Neville, H. 1996. Maturational constraints on functional specializations for language processing: ERP and behavioral evidence in bilingual speakers. J . Cogn. Neurosci. 8: 231256.

Weekes, B., Chen, M. J ., and Lin, Y. B. 1998. Differential effects of phonological priming on Chinese character recognition. Read. Writ. 10: 201-222.

Wise, R., Choller, F., Hadar, U., Friston, K., Hoffner, E., and Frackowiak, R. S. J. 1991. Distribution of cortical neural networks involved in word comprehension and word retrieval. Brain 114: 1803-1807.

Xiong, J ., Gao, J .-H., Lancaster, J . L., and Fox, P. T. 1995. Clustered pixels analysis for functional MRI activation studies in the human brain. Hum. Brain Mapp. 3: 209-223.

Xiong, J ., Stofer, K., Pu, Y., Liu, H., Tan, L. H., Gao, J. H., and Fox, P. T. 2000. Possible different language processing strategy for Chinese speakers. In Proceedings of the 8th Annual Meeting of the International Society for Magnetic Resonance in Medicine, p. 900. Denver, Colorado.

Zatorre, R. J ., Evans, A. C., Meyer, E., and Gjedde, A. 1992. Lateralization of phonetic and pitch discrimination in speech processing. Science 256: 846-849. 